\title{
DIRECT SOLUTION TO PRACTICAL PROBLEM OF OPEN CHANNEL FLOW FOR HORIZONTAL TRANSITIONS
}

\author{
By \\ Sobeih, M. F. \\ Assoc. Prof., Civil Engineering Dept., Faculty of Engineering, Minufiya University.
}

\begin{abstract}
Horizontal transitions are required for economic and practical reasons for irrigation works like bridges, weirs and barrages in natural and artificial open channels. The transitions may be contracting or expanding suddenly or gradually while the flow is either subcritical or supercritical. The problem is solved using the specific energy principle. Most of the previous researches solved the problem neglecting the head loss (theoretical solution).

The author presents in this research paper a new approach to solve the problem for horizontal transition for rectangular open channels.

The specific energy equation in this paper takes a real condition in consideration for both contracting and expanding problems. The practical horizontal transitions cases are solved taking into consideration the head loss due to contracting or expanding. Also, this research paper deals with the problem of channel section while contracting with amount greater than that of critical one. If the contraction of bed is increased further, the maximum $b_{c}$ and the specific energy were both held constant with this contraction, the discharge will be decreased until the given specific energy is equal to minimum one corresponding to the new discharge, because the energy cannot be increased without outside affect. Consequently the upstream water depth will be changed to a new value.
\end{abstract}

\footnotetext{
Manuscript received from Dr. M.F. Sobeih

Accepted on : $23 / 9 / 2002$

Engineering Research Journal Vol 25, No 4, 2002 Minufiya University, Faculty Of

Engineering, Shebien El-Kom, Egypt, ISSN 1110-1180
} 


\section{INTODUCTION}

The horizontal transition problems can be solved by the specific energy equation which takes the following simplest form (for a channel of very small slope and $\alpha \approx 1.0$ ) (Fig. (1)):

$$
E=y+\frac{V^{2}}{2 g}
$$

in which: $E$ is the specific energy; $y$ is the water depth; $\alpha$ is the energy coefficient; $V$ is the mean velocity normal to water area; and $g$ is the acceleration due to gravity. Since $Q=A . V$ Equation (1) may be written as follows:

$$
E=y+\frac{Q^{2}}{2 g A^{2}}
$$

in which: $Q$ is the discharge; and $A$ is the water cross-sectional area.

Solving for Q:

$$
Q=A \sqrt{2 g(E-y)}
$$

Equation (2) is presented graphically in Fig. (2).

The curve shows that, for a given discharge, there are two possible water depths, the low stage $y_{1}$ and the high stage $y_{2}$. The low stage is called supercritical flow. The high stage is called subcritical flow. The two water depths are called alternative water depths. If the specific energy changes, the discharge will be changed accordingly. It means that very specific energy has a specific curve for a certain discharge $Q$.

\section{Practical Horizontal Transition Problems:}

When the size or shape of the cross section of an open channel changes along the length through a horizontal transition, it should be considered as a link between the original and the new channel. Horizontal transitions may be either contracting or expanding, suddenly or gradually taking a short distance or a long one. This research paper is relevant to the solution of the practical problem while the head loss is considered. Thus, the solution of the problem using the specific energy equation takes the following shape:

$$
\begin{gathered}
E_{1}=E_{2}+h_{l} \\
y_{1}+\frac{Q^{2}}{2 g A_{1}{ }^{2}}=y_{2}+\frac{Q^{2}}{2 g A_{2}{ }^{2}}+h_{l}
\end{gathered}
$$

in which: $E_{1}$ is the specific energy upstream the transition; $E_{2}$ is the specific energy downstream the transition; $h_{l}$ is the head loss due to the transition; $y_{1}$ is the water depth at upstream the transition; $y_{2}$ is the water depth downstream the transition; $A_{1}$ is the water cross-sectional upstream the transition; and $A_{2}$ is the water cross-section downstream the transition.

For rectangular section Formica [1] applied the following equations to the energy loss in open channel with a horizontal transitions, as follows:

Case I: For a sudden contraction:

$$
h_{l}=K \frac{V^{2}}{2 g}
$$


in which: $K$ is coefficient of the head loss due to the contraction.

The approximate median value of $K$ for sudden contraction is 0.1 and, for flared or moderate is 0.06 (Fig. (3)).

Case II: For a sudden expansion:

$$
h_{l}=\varepsilon \frac{\left(V_{1}-V_{2}\right)^{2}}{2 g} \text {. }
$$

in which: $\varepsilon$ is the coefficient of head loss due to expansion. $V_{1}$ is the water velocity upstream the transition; and $V_{2}$ is the water velocity downstream the transition.

Formica obtained average values of $\varepsilon$ for eight sudden expansion shapes which varied between 0.82 and 0.44 [1].

Substituting Equation (4) in Equation (3) for practical sudden contraction problem for rectangular open channels, the following equation is obtained:

$$
\begin{gathered}
y_{1}+\frac{Q^{2}}{2 g\left(b_{1} y_{1}\right)^{2}}=y_{2}+\frac{Q^{2}}{2 g\left(b_{2} y_{2}\right)^{2}}+K \frac{Q^{2}}{2 g\left(b_{2} y_{2}\right)^{2}} \\
E_{1}=y_{2}+(1+K) \frac{Q^{2}}{2 g b_{2}{ }^{2} y_{2}{ }^{2}} \\
1=\frac{y_{2}}{E_{1}}+(1+K) \frac{Q^{2}}{2 g b_{2}{ }^{2} E_{1} y_{2}{ }^{2}}
\end{gathered}
$$

in which: $b_{1}$ is the section breadth upstream the transition; and $b_{2}$ is the section breadth downstream the transition.

Putting dimensionless parameters $Q_{*}=\sqrt{\frac{Q^{2}}{2 g b_{2}{ }^{2} E_{1}{ }^{3}}}$, and $y_{*}=y_{2} / E_{1}$ the above equation takes the following form:

$$
\begin{gathered}
1=y_{*}+(1+K) \frac{Q_{*}{ }^{2}}{y_{*}{ }^{2}} \\
y_{*}{ }^{2}=y_{*}{ }^{3}+Q_{*}{ }^{2}+K y_{*}{ }^{2} \\
Q_{*}=y_{*} \sqrt{(1-K)-y_{*}} \ldots \ldots
\end{gathered}
$$

in which: $Q_{*}$ is the dimensionless discharge; and $y_{*}$ is the dimensionless water depth.

Equation (6) is plotted in a graphical shape in Fig. (4). The figure shows three curves for $K=0.0$ (theoretical) and $K=0.1$ and 0.06 for real contraction.

The following are displaying some problems that usually in the hydraulic design for the horizontal transitions (contracting).

1. To estimate the size of contracting just required to make the flow critical $\left(b_{2}=b_{c}\right)$ (which may be termed as critical contraction);

2. To predict the flow after the transition when the transition is smaller than the critical value $\left(b_{2}<b_{c}\right)$;

3. To predict the flow after the transition as well as upstream when the size of contraction is larger than the critical size $\left(b_{2}>b_{c}\right)$.

To get the condition of maximum contracting differentiates the discharge to the depth and equate to the zero as: 


$$
\begin{aligned}
& \frac{d Q_{*}}{d y_{*}}=y_{*}\left(\frac{1}{2}\right)\left(\frac{1}{\sqrt{(1-K)-y_{*}}}\right)(-1)+\sqrt{(1-K)-y_{*}}=0.0 \\
& y_{* c}=\frac{2}{3}(1-K) \ldots \ldots \ldots \ldots \ldots \ldots \ldots \ldots \ldots \ldots \ldots \ldots \ldots \ldots \ldots \ldots \ldots \ldots \ldots \ldots \ldots \ldots \ldots \ldots \ldots \ldots \ldots \ldots \ldots \ldots
\end{aligned}
$$

Substituting Equation (7) into Equation (6) it can be obtained:

$$
\begin{aligned}
& Q_{*_{c}}=y_{*_{c}} \sqrt{1-y_{*_{c}}-1+1.5 y_{*_{c}}} \\
& Q_{*_{c}}{ }^{2}=0.5 y_{*_{c}}{ }^{3} \ldots \ldots \ldots \ldots \ldots \ldots
\end{aligned}
$$

in which: $Q_{* c}$ is the dimensionless critical discharge; and $y_{* c}$ is the dimensionless critical water depth.

$$
\text { or: } \quad Q_{*_{c}}=\frac{1}{\sqrt{2}} y_{* c}^{3 / 2}
$$

\section{Demonstration of the Proposed Method}

\section{Case of contracting:}

As mentioned before the approximate median value of $K$ for sudden contraction is 0.1 and for flared or moderate is 0.06 , then the corresponding values of $y_{* c}=0.6,0.627$ and $Q_{*_{c}}=0.3286,0.351$ respectively.

There are three cases of contracting according to the amount of contraction of the breadth as following:

- Case I: if $b_{2}=b_{c}$.

- Case II: if $b_{2}>b_{c}$.

- Case III: if $b_{2}<b_{c}$

\section{Case I: $\left(b_{2}=b_{c}\right)$}

For given $Q, b_{1}$, and $y_{1}$ and if $b_{2}=b_{c}$, then:

To solve this problem compute the upstream specific energy $E_{1}=y_{1}+\frac{Q^{2}}{2 g b_{1}^{2} y_{1}^{2}}$ and substituting the value of the dimensionless parameter $Q_{*_{c}}=0.3826$ or 0.351 according to the case of contraction. Then for $b_{2}=b_{c}$ the following equation can be derived:

$$
b_{c}=\sqrt{\frac{Q^{2}}{2 g Q_{*_{c}}^{2} E_{1}^{3}}}
$$

Case 1I: $\left(b_{2}>b_{c}\right)$

For given $Q, b, y_{1}$, and $b_{2}$ and to derive an expression for $y_{2}$ the following steps are followed:

Compute the practical critical contraction using the same steps as in case I.

Check that $b_{2}>b_{c}$

By using the values of $Q_{*}$ and $\mathrm{K}$ get $y_{* 2}$ from the Equation (6), where $y_{* 1}<y_{* 2}<y_{* c}$ if the flow is supercritical and $\left.y_{* 1}\right\rangle y_{* 2}>\mathrm{y}_{* \mathrm{c}}$ if the flow is subcritical.

From any of the two states of flow, the downstream water depth can be calculate as following:

$$
y_{2}=y_{* 2} \cdot E_{1}
$$




\section{Case III: $\left(b_{2}<b_{c}\right)$}

If the contraction is increased further (i.e.: above critical contraction), then in order to pass the same discharge the specific energy will have to be increased. In this case, if the flow approaching the contracting section is subcritical, the specific energy would be increased, providing a rise of the water depth at section 1 (refer to Fig. (1)). Similarly, if the flow approaching the contraction is supercritical, the water depth of flow at section 1 would be reduced, thereby providing an increase in the specific energy.

$$
\begin{gathered}
E_{1}^{\prime}=E_{2 c}+h_{l} \\
y_{1}^{\prime}+\frac{Q^{2}}{2 g\left(b_{1} y_{1}^{\prime}\right)^{2}}=y_{2 c}+\frac{Q^{2}}{2 g\left(b_{2} y_{2 c}\right)^{2}}+h_{l}
\end{gathered}
$$

However, if the specific energy is held constant $\left(E_{1}-h_{l}\right)$ in the contracting section with a value more than the above which indicates a limiting value (critical contraction), the discharge is decreased until the given specific energy is equal to the minimum specific energy corresponding to the new discharge, because the energy cannot be increased without outside affect.

For given $Q, b_{l}, y_{l}$, and $b_{2}$ and it is required to derive expressions for: $\bar{Q}$ and $\overline{y_{1}}$, the following steps of solution would be done as follows:

Compute the practical critical contraction using the same steps as in case I.

Check that $b_{2}<b_{c}$ and then compute the upstream specific energy $E_{1}=y_{1}+\frac{Q^{2}}{2 g b_{1}^{2} y_{1}^{2}}$ and the value of the dimensionless critical discharge $Q_{* c}=0.3826$ or 0.351 according to the case of contraction. The new discharge is obtained from the following equation:

$$
\bar{Q}=\sqrt{2 g b_{2}{ }^{2} E_{1}^{3} Q_{*}{ }^{2}}
$$

The new upstream water depth is calculated from the following equations in terms of the known values of $y_{* 2 c}=0.6,0.627$ according to the case of contraction; as follows:

$$
\begin{aligned}
& Q_{* 1}=\sqrt{\frac{\bar{Q}^{2}}{2 g b_{1}^{2} E_{1}^{3}}} \\
& E_{1}=\overline{y_{1}}+\frac{\bar{Q}^{2}}{2 g \dot{b}_{1}^{2} \bar{y}_{1}^{2}} \\
& \text { and: } \quad \overline{Q_{* 1}}=\overline{y_{* 1}} \sqrt{1-\bar{y}_{* 1}} \\
& \overline{y_{1}}=\overline{y_{* 1}} \cdot E_{1}
\end{aligned}
$$

\section{Case of Expanding:}

Substituting Equation (5) in Equation (3) for practical sudden contraction problem the following equation is obtained:

$$
\begin{array}{ll}
y_{1}+\frac{Q^{2}}{2 g\left(b_{1} y_{1}\right)^{2}}=y_{2}+\frac{Q^{2}}{2 g\left(b_{2} y_{2}\right)^{2}}+\varepsilon \frac{\left(V_{1}-V_{2}\right)^{2}}{2 g}, \\
\text { or: } \quad y_{1}+\frac{Q^{2}}{2 g\left(b_{1} y_{1}\right)^{2}}=y_{2}+\frac{Q^{2}}{2 g\left(b_{2} y_{2}\right)^{2}}+\varepsilon \frac{V_{2}^{2}\left(b_{2} y_{2} / b_{1} y_{1}-1\right)^{2}}{2 g},
\end{array}
$$


then:

$$
E_{1}=y_{2}+\frac{Q^{2}}{2 g\left(b_{2} y_{2}\right)^{2}}\left[1+\varepsilon\left(b_{2} y_{2} / b_{1} y_{1}-1\right)^{2}\right]
$$

Putting dimensionless parameters $Q_{*}=\sqrt{\frac{Q^{2}}{2 g b_{2}^{2} E_{1}^{3}}}, y_{* 1}=y_{1} / E_{1}$ and $y_{*}=y_{2} / E_{1}$ then the above equation takes the form:

$$
1=y_{*}+\frac{Q_{*}^{2}}{y_{*}^{2}}\left[1+\varepsilon\left(\left(\frac{b_{2}}{b_{1}} \frac{y_{*}}{y_{*}}\right)-1\right)^{2}\right]
$$

solving for $Q_{*}$ :

$$
Q_{*}=y_{*} \sqrt{\frac{\left(y_{*}-1\right)}{\left[1+\varepsilon\left(\left(\frac{b_{2}}{b_{1}} \frac{y_{*}}{y_{*}}\right)-1\right)^{2}\right]}}
$$

To solve this problem in which: $Q, b_{1}, y_{1}$, and $b_{2}$ are given; an expression for $y_{2}$ is obtained. Thus, $E_{1}, Q_{*}$, and $y_{* 1}$ can be computed. So, $y_{* 2}$ for the supercritical flow, and i $y_{* 2}$ for subcritical flow can be calculated. Consequently, the downstream water depth can then be expressed as follows, as an example, considering any one of the states of flow. From any of the two states of flow it can be calculate the downstream water depth as following:

\section{CONCLUSIONS}

$$
y_{2}=y_{* 2} \cdot E_{1}
$$

1-When the channel section is contracting or expanding, it can be easily solved as a horizontal transition problem by taking the value of head loss into consideration, it may be considered as practical problems with real characteristics.

2-The horizontal transition problems can be classified into two types:

I- Contraction in open channel rectangular cross section

The practical contracting problems can then be solved using one single equation.

Considering the approximate median value of $\mathrm{K}$ for sudden contraction is 0.1 and, for flared or moderate is 0.06 , then the corresponding values of $y_{* c}=0.6$, 0.627 and $Q_{* c}=0.3286,0.351$ respectively. The problem of horizontal transitions with real (practical) case can be solved as one from three cases $b_{2}=b_{c}, b_{2}<b_{c}$ and $b_{2}>b_{c}$. If the contraction of bed is increased further than the maximum $b_{c}$ and the specific energy held constant with the same contraction, the discharge will be decreased until the given specific energy is equal to the minimum specific energy corresponding to the new discharge, because the energy cannot be increased without outside affect. Also, the upstream water depth will be changed to a new value $\overline{y_{1}}$.

II- Expansion in open channel rectangular cross section

The practical expanding problems are solved by the new derived Equation (17) in terms of the dimensionless discharge $Q_{*}$.

The approximate median values of $\varepsilon$ for eight sudden expansion shapes are varied between 0.82 and 0.44 . 
3-The practical solution gives changeable values of solution compared to the theoretical one.

\section{REFERENCES}

1- Chow, V. T., "Open Channel Hydraulics" McGraw-HILL, 1959.

2- Henderson, F. M, "Open Channel Flow", The Macmillan Co., New York, N.Y.

3- Modi, P. N. and Seth, S. M., "Hydraulics and Hydraulics Machines", New Delhi, 1968.

4- Nanndana Vitall, "Direct Solution to Problems of Open Channel Transitions", Journal of the Hydraulics Division, ASCE, Vol. 104, No. HY11, November, 1978.

5- Owais, T. M., "Open Channel Flow and Hydraulic Modeling", Lecture Notes , ElMansoura University , Egypt, 1976.

6- Rashwan, I. M. H., "Flow Characteristics Through Horizontal Transitions", Master thesis, presented to Mansoura University, Faculty of Engineering, 1987.

\section{NOTATIONS}

The following symbols are used in this research paper:

$A \quad=$ the water cross-sectional area;

$A_{1}=$ the water cross-sectional upstream the transition;

$A_{2}=$ the water cross-section downstream the transition;

$b \quad=$ the section breadth;

$b_{1} \quad=$ the breadth upstream the transition;

$b_{2} \quad=$ the breadth downstream the transition;

$b_{c} \quad=$ the critical breadth of section;

$E \quad=$ the specific energy;

$E_{1} \quad=$ the specific energy upstream the transition;

$E_{l}^{\prime} \quad=$ the affected water depth upstream the transition;

$E_{2} \quad=$ the specific energy downstream the transition;

$E_{2 c} \quad=$ the specific energy downstream the transition (critical section);

$g \quad=$ the acceleration due to gravity;

$K \quad=$ coefficient of the head loss due to contraction;

$Q \quad=$ the discharge;

$\bar{Q} \quad=$ the new discharge upstream the transition;

$Q_{*} \quad=$ the dimensionless discharge;

$\overline{Q_{*}} \quad=$ the new dimensionless discharge at the upstream of the transition;

$Q_{*_{c}} \quad=$ the critical dimensionless discharge;

$V \quad=$ the main velocity;

$V_{1} \quad=$ the main velocity upstream the transition;

$V_{2} \quad=$ the main velocity downstream the transition; 


$$
\begin{array}{ll}
y & =\text { the water depth. } \\
y_{1} & =\text { the water depth upstream the transition; } \\
\frac{y_{1}^{\prime}}{y_{1}} & =\text { the affected water depth upstream the transition; } \\
\frac{y_{*}}{y_{2}} & =\text { the new water depth upstream the transition; } \\
y_{2 c} & =\text { the water depth downstream the transition; } \\
y_{*} & =\text { the dimensionless water depth; } \\
y_{*} & =\text { the dimensionless critical depthof flow; } \\
\alpha & =\text { the energy coefficient; }
\end{array}
$$




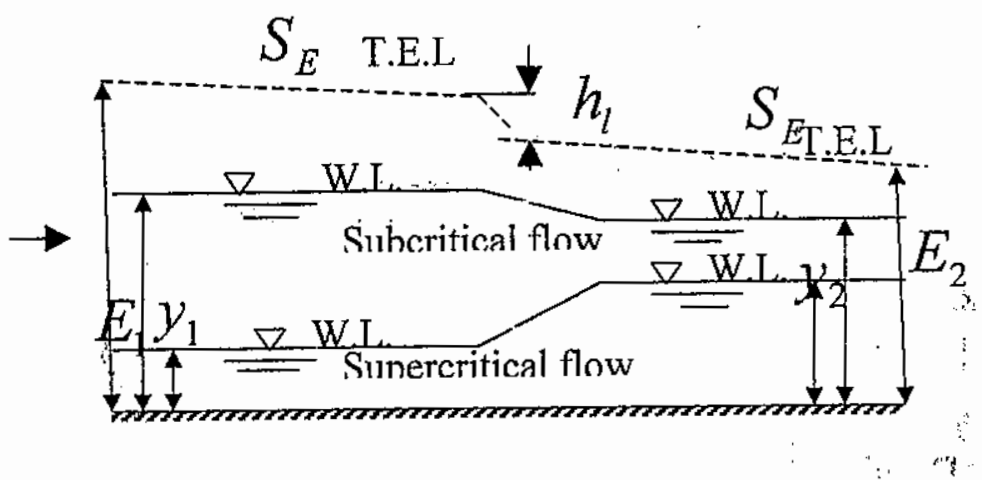

Flevation

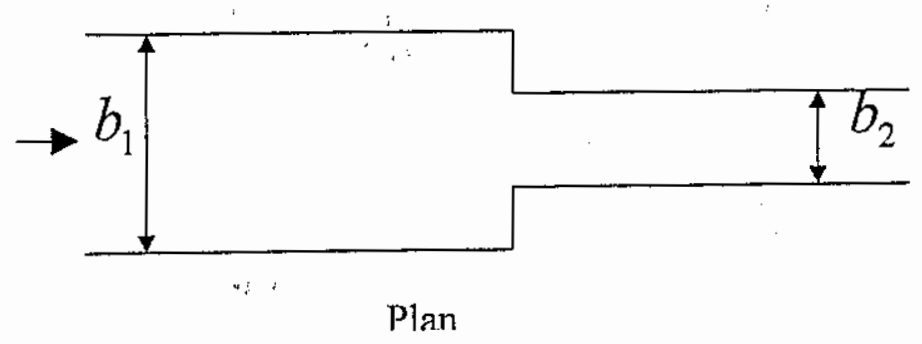

(a) Contracting.

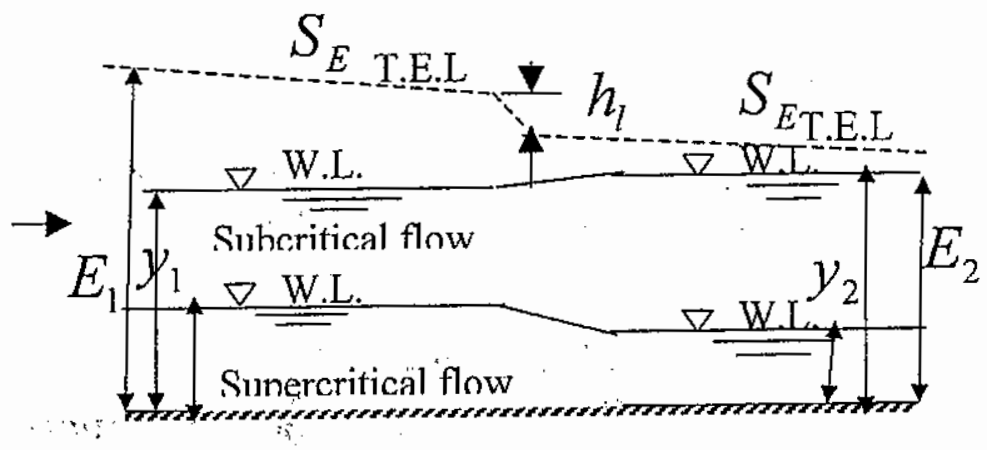

Flevation

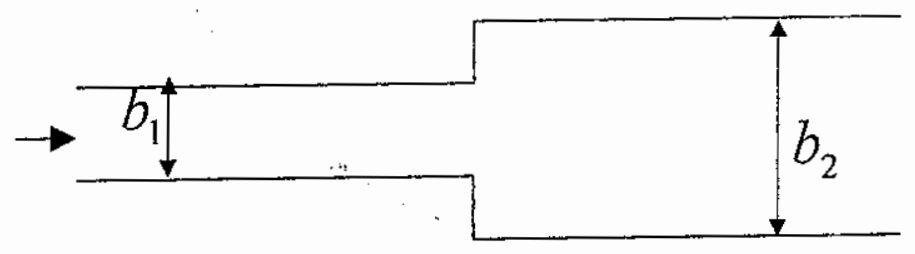

Plan

(b) Expanding.

Fig. (1) Horizontal Transitions Problem. 


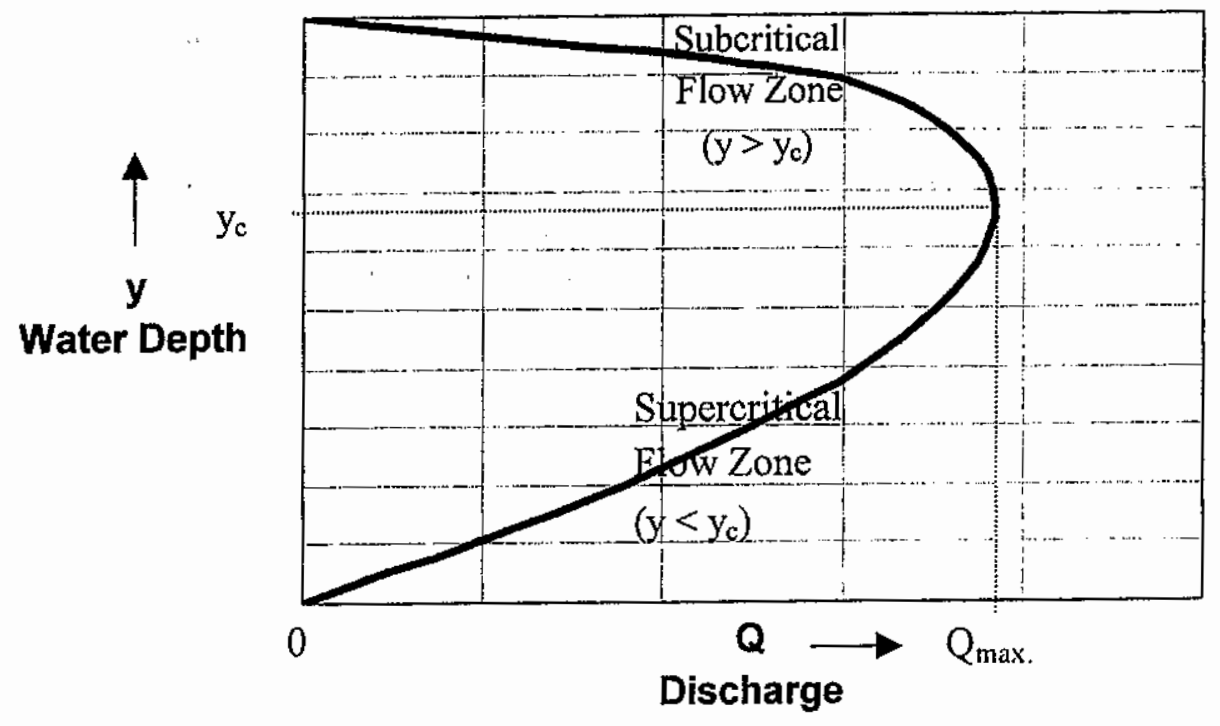

Fig. (2) Definition Sketch for the Specific Discharge Curve.

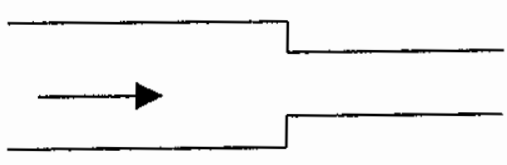

(a) Sudden ( $K=0.1$ )

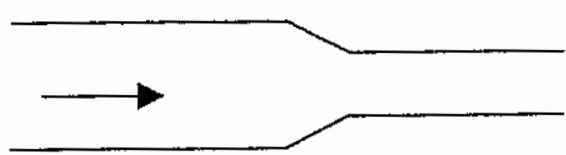

(b) Flared $(K=0.06)$.

Fig. (3) Various Shapes of Contraction.

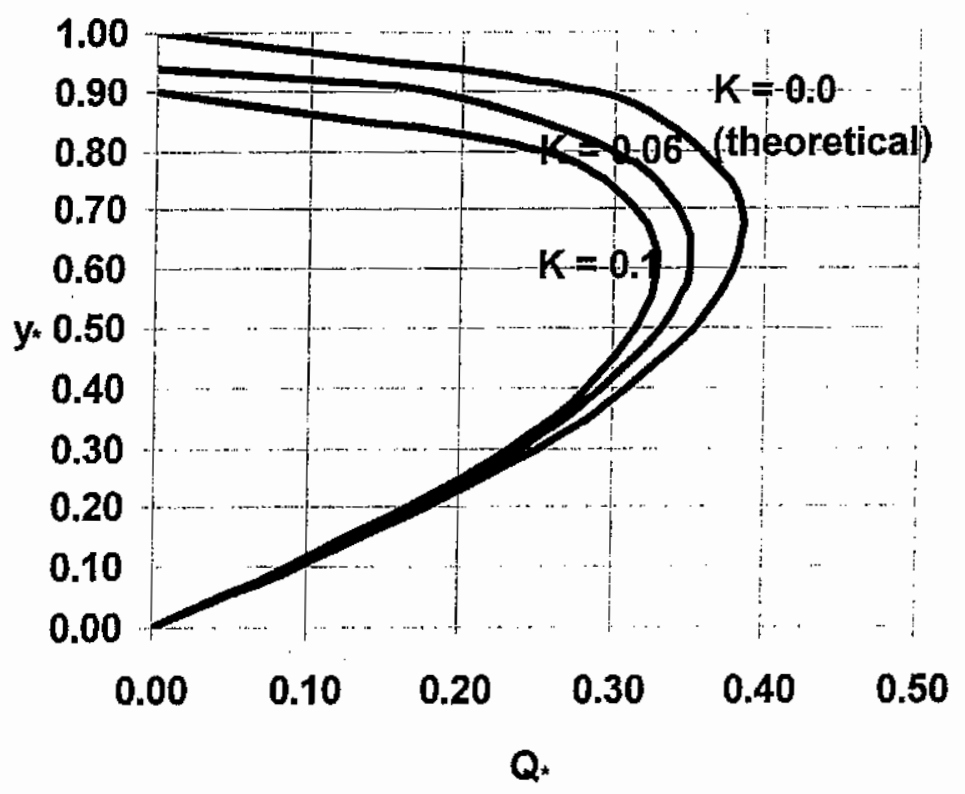

Fig. (4) Specific Dimensionless Discharge Curves for Contracting. 
الحل المباثر لمسألة التغير الأفقى الحقيقي العملى للسريان فى القتوات المفتوحة أ.م.د/محمد محمد فؤاد صبيح

\section{الخلاصة:}

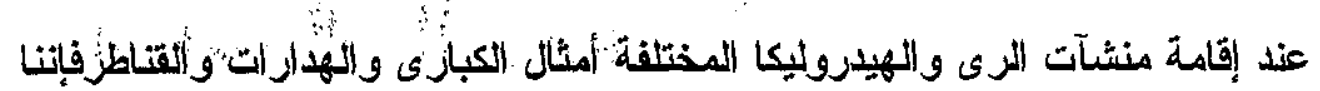
دأئما فى حاجة إلى تغيير المجرى المائى تضييقا أو توسيعا. وعند تغيير المجرى المائى المئى

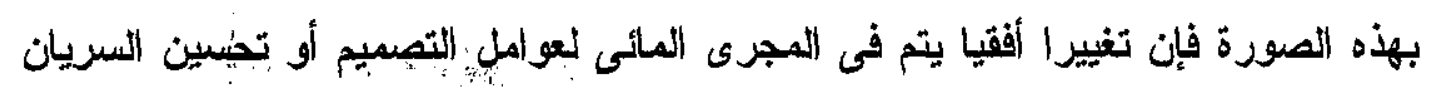

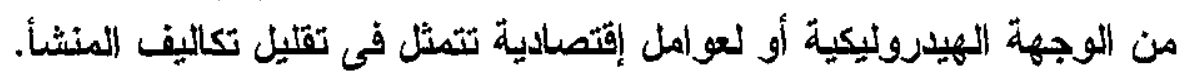
ومسألة التغير الأفقى يمكن حلها بواسطة معادلة الطاقة النوعية وحيث أن معادلة الطاقة فئة

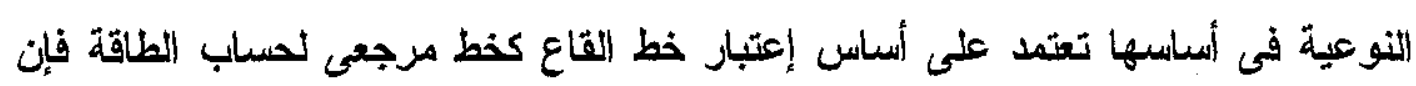

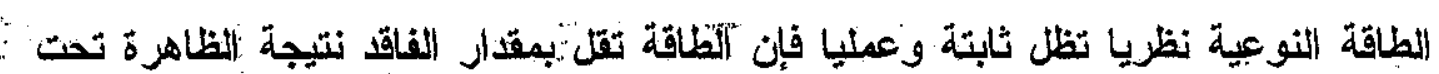
اللدر أسة سواء تضبيق أو توسبع.

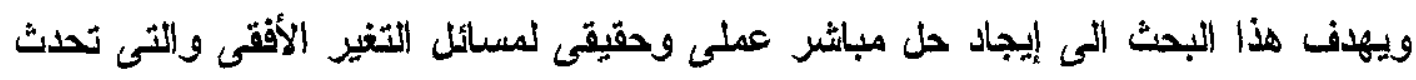

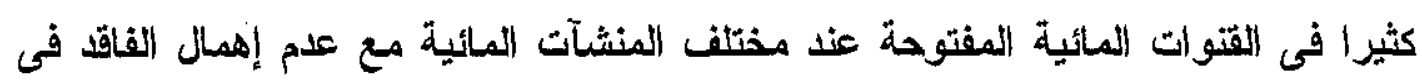
الطاقة نتيجة التخير الأققى.

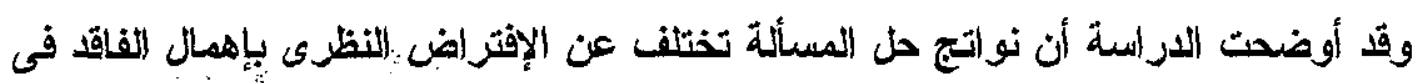

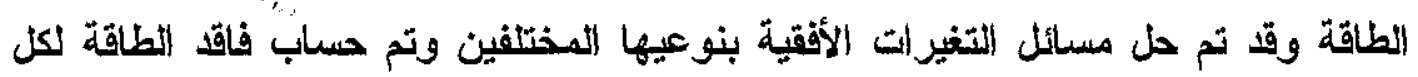
نوع على حدة لقطاع ذو شكل مستطيل وإجمالا فقل تم حل المسائل التالية:

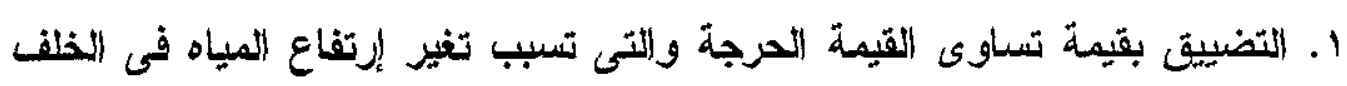

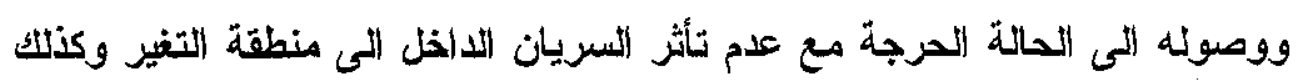

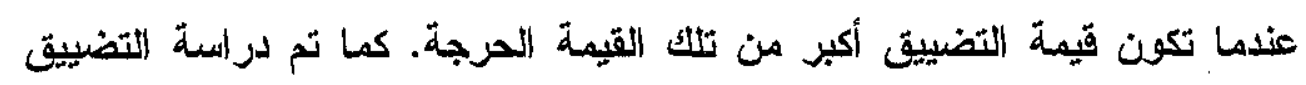

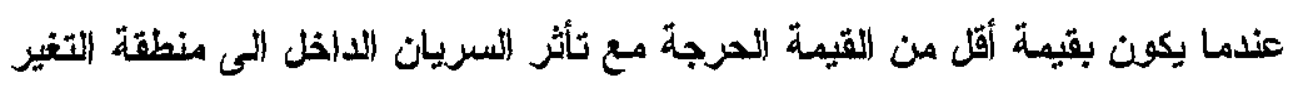

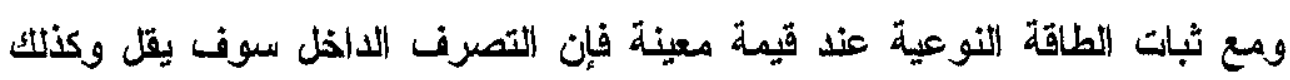

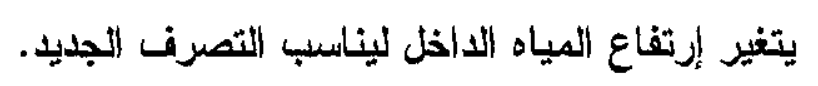

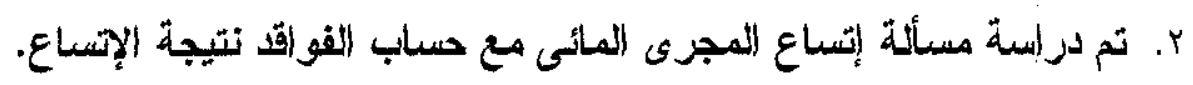

